\title{
A TRICKLE-DOWN MODEL OF ABUSIVE SUPERVISION
}

\author{
MARY BARDES MAWRITZ \\ Drexel University \\ DAVID M. MAYER \\ University of Michigan \\ JENNY M. HOOBLER \\ University of Illinois \\ SANDY J. WAYNE \\ University of Illinois \\ SOPHIA V. MARINOVA \\ University of Illinois
}

\begin{abstract}
Much of the abusive supervision research has focused on the supervisorsubordinate dyad when examining the effects of abusive supervision on employee outcomes. Using data from a large multisource field study, we extend this research by testing a trickle-down model of abusive supervision across 3 hierarchical levels (i.e., managers, supervisors, and employees). Drawing on social learning theory and social information processing theory, we find general support for the study hypotheses. Specifically, we find that abusive manager behavior is positively related to abusive supervisor behavior, which in turn is positively related to work group interpersonal deviance. In addition, hostile climate moderates the relationship between abusive supervisor behavior and work group interpersonal deviance such that the relationship is stronger when hostile climate is high. The results provide support for our trickle-down model in that abusive manager behavior was not only related to abusive supervisor behavior but was also associated with employees' behavior 2 hierarchical levels below the manager.
\end{abstract}

Abusive supervision is defined as "subordinates' perceptions of the extent to which their supervisors engage in the sustained display of hostile verbal and nonverbal behaviors, excluding physical contact" (Tepper, 2000, p. 178). Examples include a supervisor telling a subordinate that his or her thoughts or feelings are stupid or putting the subordinate down in front of others. There is compelling evidence that abusive supervision results in negative employee attitudes, behaviors, and psychological health (e.g., Mitchell \& Ambrose, 2007; Tepper, 2000; Tepper, Henle, Lambert,

Correspondence and requests for reprints should be addressed to Mary Bardes Mawritz, Department of Management, LeBow College of Business, 101 N. 33rd Street, Philadelphia, PA19104; meb359@drexel.edu. 
Giacalone, \& Duffy, 2008). Yet, it is unclear whether these negative outcomes occur only at the dyadic level, affecting only the subordinate of the abusive supervisor, or whether they extend beyond the dyad to negatively influence the outcomes of lower-level employees. To address these questions, researchers have begun to incorporate abusive supervision as one link in a chain of aggressive workplace events (e.g., Aryee, Chen, Sun, \& Debrah, 2007; Hoobler \& Brass, 2006). These studies attempt to answer a call sounded by Andersson and Pearson (1999) to define precursors of workplace aggression by investigating responses to mistreatment as a related system of social interactions. In line with this new interest, our paper examines abusive supervision as a socially embedded phenomenon by developing and testing a trickle-down model of abusive behavior.

Our theoretical model is in line with a growing body of research on trickle-down models that link behaviors of higher levels of management ${ }^{1}$ to employees' attitudes and behaviors through the behaviors of immediate supervisors. Work on trickle-down models has mainly focused on how positive aspects of management, such as charismatic leadership, ethical leadership, perceived support, and behavioral integrity at higher levels can influence employees at lower levels (e.g., Bass, Waldman, Avolio, \& Bebb, 1987; Mayer, Kuenzi, Greenbaum, Bardes, \& Salvador, 2009). More recently, trickle-down models have been used to describe how negative aspects of leadership, such as injustice (e.g., Aryee et al., 2007; Tepper, Duffy, Henle, \& Lambert, 2006) and violations of psychological contracts (Hoobler \& Brass, 2006), trickle down from higher levels of management to lower-level employees. Our trickle-down model contributes to this line of research.

To develop our trickle-down model of abusive supervisor behavior, we apply social learning theory (Bandura, 1977, 1986). We posit that supervisors role model the abusive behavior of their managers and engage in similar abusive behavior with their own employees. In other words, abusive manager behavior indirectly impacts employees who hold positions two hierarchical levels below the manager through its effect on abusive supervisor behavior. As links in a chain of interpersonal relationships, we predict that abusive manager behavior will be positively related to abusive supervisor behavior, and that abusive supervisor behavior will be associated with abusive employee behavior-namely, work group

\footnotetext{
${ }^{1}$ In this paper, we use the term manager to refer to the supervisor's boss. Typically, these managers are in middle- or upper-level management positions. We use the term supervisor to refer to front-line managers who interact on a daily basis with lower-level employees and who report to the managers at mid- or upper-levels. Thus, the term supervisor refers to those in lower-level management positions. Finally, we use the term employees to refer to the supervisor's subordinates who are typically at the lowest level in the organization and who report to the supervisor.
} 


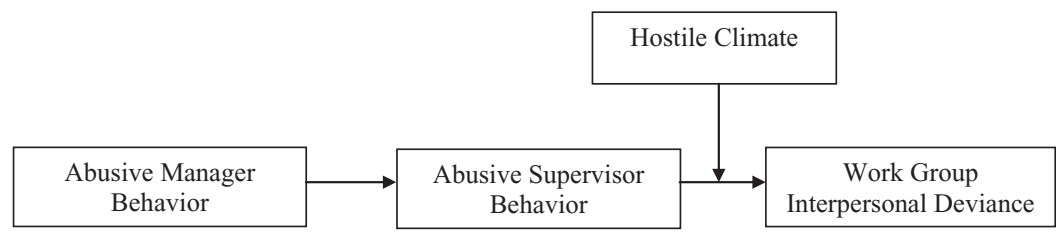

Figure 1: Theoretical Model of the Trickle-Down Effect of Abusive Supervision.

interpersonal deviance (i.e., employees' abusive behaviors directed at other organizational members). Finally, we examine hostile climate, defined as consistent acrimonious, antagonistic, and suspicious feelings within the work group, as a moderator of the relationship between abusive supervisor behavior and work group interpersonal deviance, such that the relationship is expected to be stronger when the hostile climate of the work group is high as opposed to low. To make this assertion, we draw on both social learning and social information processing theories to suggest that employees will look to the social context for information regarding perceived norms and will use this information in deciding to role model their supervisors' abusive behaviors. Our theoretical model is presented in Figure 1.

Our study seeks to make a number of specific contributions. First, in contrast to the majority of research on abusive supervision that examines the effects of abusive supervisors on lower level employee attitudes and behaviors, we explore the role of abusive behavior at higher levels and how such behavior may trickle down and negatively impact lower level employees. Given that organizations are hierarchically structured and contain systems of social interactions, a multilevel examination of abusive supervision is essential.

Second, much of the research on abusive supervision has focused on outcomes of this behavior. We explore an outcome of abusive supervisor behavior, namely work group interpersonal deviance, but in addition, we examine abusive manager behavior as an antecedent. Such an examination is warranted as there is a paucity of research on antecedents of abusive supervision and still much to be investigated in this area.

Third, the limited research on trickle-down effects of negative forms of leadership has examined their effect on employees' positive job attitudes and behaviors (e.g., Aryee et al., 2007), but has yet to examine negative behavioral outcomes. In addition, recent work on the trickle-down effect has not explicitly examined how abusive behavior, in particular, trickles down from one organizational level to the next. For example, Aryee et al. examined a supervisor's perceptions of interactional justice (not higher 
level manager abusive supervision) as an antecedent of a supervisor's abusive behavior and examined the relationship between this abusive behavior and employee perceptions of interactional justice and positive behavioral and attitudinal outcomes (e.g., citizenship behavior and affective commitment). Thus, we attempt to address this gap in the literature by specifically examining the trickle-down effect of abusive supervisory behaviors.

Fourth, in addition to a lack of research on the trickle-down effect of negative behaviors, the moderating effects of contextual factors have received limited attention. Some scholars have examined supervisors' characteristics as moderators of the trickle-down effect (e.g., supervisors' authoritarianism; Aryee et al., 2007; supervisors' hostile attribution bias; Hoobler \& Brass, 2006), but aspects of the work environment have yet to be investigated as moderators. In our study, we address this question by examining hostile climate in the work group as a contextual moderator. In what follows, we discuss our conceptualization of our theoretical constructs and provide the rationale for our theoretical model and hypotheses.

\section{Literature Review and Hypotheses}

\section{Work Group Level of Analysis}

We conceptualize abusive manager behavior, abusive supervisor behavior, hostile climate, and interpersonal deviance at the work group level. These constructs are treated as shared unit properties. Three theories provide explanations for why these constructs emerge at the group level. First, social information processing theory suggests work group members use information from the immediate work context to interpret events and develop expectations about appropriate behaviors (Salancik \& Pfeffer, 1978). Members of the same work group are exposed to the same work environment and similar cues regarding behavioral norms. Thus, they usually have similar perceptions of what constitutes acceptable behavior and tend to behave in a fairly homogenous manner. Second, social learning theory suggests individuals strive to emulate the behaviors of role models (e.g., other members of the work group) in their work environments (Bandura, 1977). The theory suggests individuals within a work group model the behaviors of others to ensure that their own behavior coincides with acceptable norms. Thus, work group members tend to imitate each other and thereby engage in similar behaviors. Finally, the attractionselection-attrition (ASA) model suggests individuals are attracted to and selected into work groups based on the fit between their personal attributes and those of the work group (Schneider, 1987). Individuals are likely to be attracted to and selected into groups that they fit with, will remain a 
member of the group as long as their behavioral tendencies fit with other members, and will leave the group if they do not fit. The result is a work group with members who have similar views regarding behavioral norms and, hence, similar behaviors. Taken together, although these theoretical frameworks vary in terms of underlying processes, all three predict the emergence of group-level behavioral constructs.

In addition to this theoretical support for the emergence of behaviors as a group-level construct, there is mounting empirical evidence that supports the examination of deviant behavior in particular at the group level (e.g., Brown \& Treviño, 2006; Mayer et al., 2009; Robinson \& O'Leary-Kelly, 1998). This research has examined antecedents (e.g., socialized charismatic leadership, value congruence, top manager ethical leadership) and consequences (e.g., individual-level deviance, aggression, satisfaction, and turnover intentions) of group-level deviance and has found that employees tend to have shared perceptions regarding the levels of deviance within a work group.

\section{The Trickle-Down Effect of Abusive Supervision}

In addition to explaining why behavioral constructs emerge at the group level, social learning theory can be used as theoretical support for our trickle-down model of abusive supervision. According to social learning theory (Bandura, 1977, 1986), individuals acquire social behavior either through direct experience or by observing others. Research on social learning and behavioral role modeling has shown that human behavior is partially driven by observing behaviors of credible role models and then emulating those behaviors. To determine which behaviors are appropriate and acceptable in a given situation, individuals attend to and observe those around them, make judgments of the observed behaviors based on the consequences received, and then embark on mimicking behaviors that are deemed to have positive consequences. In describing social learning theory, Bandura suggests two primary conditions that are necessary to successful role modeling: (a) attention - the observer must attend to the model, and (b) retention- the observer must remember the observed behavior. These conditions are influenced by perceptions of a potential role model (e.g., an individual's visibility, power, credibility) as well as salience of the observed behavior.

In the organizational context, social learning theory has been used to explain the transfer of behaviors, both positive and negative, across organizational actors. Organizational members observe the behaviors of other members (e.g., supervisors, coworkers) and enact these behaviors themselves. Although most organizational research using social learning theory has focused on the transfer of positive behaviors, the theory also has 
been used to explain the proliferation of dysfunctional behavior in organizations (e.g., Dupre' \& Barling, 2006; O’Leary-Kelly, Griffin, \& Glew, 1996). In particular, the trickle-down theory of aggression (Goldstein, 1986) stems from social learning theory and proposes that individuals are likely to model the aggressive behavior of those in positions of higher status, suggesting that aggressive behaviors can trickle-down from one hierarchical organizational level to the next.

The notion of a trickle-down effect of behavior is supported by the central tenets of social learning theory. The ideas that individuals are more likely to role model behaviors that attract their attention and are committed to memory imply that subordinates are likely to observe and mimic the behaviors of their immediate supervisors. Supervisors are usually highly visible to those subordinates one hierarchical level below them. In these proximal leadership situations, subordinates are more likely to attend to and have the most contact with their immediate supervisors. Therefore, subordinates have many opportunities to observe their supervisors and gain information about appropriate behaviors from these significant authority figures (Shamir, 1995).

In addition, by the nature of their assigned, hierarchical positions, supervisors are usually deemed by subordinates to be both powerful and credible (Brown, Treviño, \& Harrison, 2005). Individuals in formal positions of authority have legitimate power over those at lower organizational levels (e.g., the ability to control rewards and punishments; French \& Raven, 1959; Yukl, 2004; Yukl \& Falbe, 1991). Positions of authority also usually coincide with perceptions of credibility. Authority figures are usually deemed to be credible because they are seen as having the necessary attributes to be promoted to higher positions (Brown et al., 2005).

Furthermore, when engaging in the leadership process (i.e., using power and influence to direct follower activities toward goal attainment; Yukl, 1998), most of a supervisor's leadership behaviors are directed at subordinates, in particular, and/or affect subordinates in one way or another. For this reason, these behaviors are likely to attract subordinates' attention. Thus, as a result of supervisors' visibility, perceived power and credibility, and the downward direction of their behaviors, subordinates are likely to look to their supervisors for information regarding behavioral norms within their organization (Berscheid, Graziano, Monson, \& Dermer, 1976).

Hence, social learning theory indicates that subordinates at lower levels look to their immediate supervisors for information on how to behave and tend to mimic their supervisors' behaviors. This will be true of supervisors emulating the behaviors of their higher level managers as well as lower level employees role modeling the behaviors of their immediate supervisors. If supervisors see their higher level managers 
engaging in abusive supervision, they may employ similar behavior but directed toward their own employees. Therefore, we first propose abused supervisors may become abusers themselves - but of those they supervise, that is, their own employees. We hypothesize that:

Hypothesis 1: Abusive manager behavior will be positively related to abusive supervisor behavior.

To fully explore the trickle-down effect, we also examine the link between abusive supervisor behavior and the abusive behaviors of lower level employees. In line with social learning arguments, research has suggested that the presence of role models in the workplace who display antisocial behavior can contribute to occurrences of workplace deviance. For example, Robinson and O'Leary-Kelly (1998) supported the contention that workers "analyze their social environments for information regarding the appropriateness of particular beliefs, attitudes, and behaviors" (p. 659) and suggested employees "watch and learn" abusive workplace patterns of interpersonal behavior from their supervisors. They also suggested that because employees are not supervisors themselves, they likely engage in these same behaviors, yet not with subordinates but with other workplace colleagues.

Abusive supervision is a form of workplace interpersonal deviance (Tepper, 2000). Interpersonal deviance is defined as voluntary behavior that violates significant organizational norms and threatens the well-being of one or more organizational members (Robinson \& Bennett, 1995). Using a social learning perspective, we propose that, in a trickle-down fashion, abused employees will emulate the abusive behaviors of their immediate supervisors by engaging in deviant behaviors directed at other organizational members. In support of this notion, recent studies have highlighted the relationship between abusive supervision and subsequent subordinate interpersonal deviance in the forms of supervisor-directed deviance (Inness, Barling, \& Turner, 2005) and self-reported interpersonal deviance (Mitchell \& Ambrose, 2007). Thus, we predict:

Hypothesis 2: Abusive supervisor behavior will be positively related to work group interpersonal deviance.

\section{The Mediating Effect of Abusive Supervisor Behavior}

Returning to our trickle-down model, we view abusive behavior in organizations as part of a system of interactions rather than a discrete event (Andersson \& Pearson, 1999). Research has shown that negative workplace events, specifically abusive behaviors, "flow downhill" to affect less powerful others (e.g., Hoobler \& Brass, 2006). We predict supervisors' 
abusive behavior is the linking pin between abusive behavior modeled by their managers and employee behavior, with abusive manager behavior flowing down the hierarchy to influence not only the individuals he or she supervises but also employees at two levels down the organizational hierarchy. Supervisors learn abusive behavior from their managers and engage in similar behaviors with their own employees. In our proposed system of social interactions, abusive supervisor behavior is the linking mechanism between abusive manager behavior and work group interpersonal deviance. Thus, we predict:

Hypothesis 3: Abusive supervisor behavior will mediate the relationship between abusive manager behavior and work group interpersonal deviance.

\section{Hostile Climate as a Moderator of the Relationship Between Abusive Supervisor Behavior and Work Group Interpersonal Deviance}

In addition to examining the trickle-down effect of abusive supervision, we also explore the work group climate as a contextual moderator of the relationship between abusive supervisor behavior and work group interpersonal deviance. There is a long history in the organizational climate literature focusing on "affective climates" (see Kuenzi \& Schminke, 2009; Schneider, Ehrhart, \& Macey, 2011). For example, one of the three facets in Ostroff's (1993) typology of climates is affective climate (Carr, Schmidt, Ford, \& DeShon, 2003). An affective climate is a specific type of climate that is an objective group phenomenon that can be "palpably sensed" (De Rivera, 1992, p. 197). Choi, Price, and Vinkour (2003) describe affective climate as an "ambient group stimuli" (p. 357) that can shape the behavioral tendencies of members of a work group. There is a considerable amount of research that has emerged in the past decade exploring the effects of affective climates on employee attitudes and behaviors (Ashkanasy \& Nicholson, 2003; Choi et al., 2003; Tse, Dasborough, \& Ashkanasy, 2008).

In the present research, we focus on a specific form of affective climate, hostile climate, because we think it is an important and theoretically relevant contextual boundary condition of the relationship between abusive supervisor behavior and work group interpersonal deviance. In line with research on affective climates (Tse et al., 2008), we define hostile climate as consistent acrimonious, antagonistic, and suspicious feelings within the work group. A hostile climate in a work group is an affective construct that occurs at the group level of analysis, is a characteristic of the group, and is a group-level phenomenon. When a hostile climate exists, 
members of the work group feel envious, less trusting, and aggressive towards others.

Consistent with the approach in this research, many scholars have examined how climate moderates the relationship between leader behaviors and follower outcomes (Chen, Lam, \& Zhong, 2007; Erdogan \& Bauer, 2010; Hofmann, Morgeson, \& Gerras, 2003; Hui, Chiu, Yu, Cheng, \& Tse, 2007; Liao \& Chuang, 2007; Walumbwa, Peterson, Avolio, \& Hartnell, 2010). The most common theoretical account for why work group climate moderates the link between leadership and employee behaviors relies on social information processing theory (Salancik \& Pfeffer, 1978). This theoretical perspective supports the notion that an individual's behavior is shaped by the behaviors of others and by contextual norms. Social information processing theory posits that an individual's behavior is influenced by others and that individuals look to those around them for cues on appropriate ways to behave. The main premise of the theory is that individuals adapt their attitudes and behaviors to their social context. The social environment provides cues that are used to interpret events and plays a role in shaping an individual's behavior by focusing his or her attention on certain information, providing expectations regarding individual behavior, and creating pressures to conform to group norms.

Thus, social information processing theory (Salancik \& Pfeffer, 1978) suggests the social context influences employees' reactions to abusive supervision. Surprisingly, there is essentially no research examining the social context as a boundary condition of the effects of abusive supervision (see Tepper, 2007 for a review, and Tepper et al., 2008 for an exception). We expect that the existence of a hostile climate in the work group may make employees' role modeling of their supervisors' abusive behaviors more likely to occur, in that a hostile climate will create a social context that will promote and encourage deviant behavior. A hostile climate in the work group will increase the salience of the supervisor's abusive behavior, making subordinates more likely to attend to the supervisor's abusive cues. In addition, the hostile climate of the group will influence subordinates' mimicry of their supervisors' behaviors by creating expectations regarding hostile behaviors and pressures to conform to norms of hostility through their own behavior. Furthermore, a hostile climate will provide validation that the supervisors' abusive behaviors are appropriate. Thus, a hostile climate within a work group will support role modeling of abusive behavior, which can increase the likelihood that a subordinate will mimic their supervisors' abusive behavior (i.e., they will engage in interpersonal deviance).

This rationale based on social information processing theory (Salancik $\&$ Pfeffer, 1978) is consistent with research examining climate as a moderator of the relationship between leader behavior and employee behavior. 
For example, Tse et al. (2008) examined affective climate as a moderator of the relationship between leader-member exchange and workplace friendship and argued that a high affective climate should strengthen the effects of leadership because "employees seek guidelines from their environment to interpret events, to develop appropriate attitudes, and to understand expectations concerning their behaviors and its consequences" (p. 200). Similarly, Hofmann et al. (2003) examined safety climate as a moderator of the relationship between leader-member exchange and safety citizenship behavior and proffered that climate-relevant behavior (i.e., safety citizenship) will be more strongly "valued" and viewed as a "legitimate avenue for reciprocating" when the climate is high (p. 171). In addition, Liao and Chuang (2007) examined service climate as a moderator of the relationship between transformational leadership and service behavior and made the claim that climate serves as a "situational enhancer" and "directs employees' attention to what leaders say and do" (p. 1009-1010). Finally, within the context of abusive supervision, Tepper et al. (2008) found abusive supervision was related to subordinates' organizational deviance through the effect it had on subordinates' affective commitment and suggested that the commitment-deviance relationship was stronger in the presence of norms toward organizational deviance. The authors defined "norms of deviance" as cues from coworkers suggesting that organization deviance is an appropriate means of expressing anger. Although Tepper et al. do not explore climate but instead focus on a different aspect of the social context in a work group (i.e., norms), they take a similar social information processing lens to understand how climate moderates the relationship between leadership and employee behavior.

In sum, we draw on evidence from social information processing theory as well as empirical studies on leadership and climate to suggest hostile climate influences the relationship between supervisor abusive behavior and work group interpersonal deviance, such that employees in work groups that have abusive supervisors will be most likely to engage in interpersonal deviance when their work group has a hostile climate. This is because employees functioning in a work group with a hostile climate come to believe that deviant behavior is supported and should be role modeled. Thus, we predict:

Hypothesis 4a: Hostile climate moderates the relationship between abusive supervisor behavior and work group interpersonal deviance such that the relationship is stronger when hostile climate is high as opposed to low.

Hypothesis 4b: Hostile climate moderates the indirect effect of abusive manager behavior on work group interpersonal deviance through abusive supervisor behavior. 
Abusive supervisor behavior will mediate the indirect effect when hostile climate is high as opposed to low.

\section{Method}

\section{Sample and Procedure}

We collected data from employees in work units in different organizations in the southeastern United States, in industries including technology, government, insurance, finance, food service, retail, manufacturing, and healthcare. We asked undergraduate students at a southeastern university to serve as organizational contacts. The students were asked to recruit a working adult (defined as working 20 hours per week or more) who was willing to serve as a focal employee. Focal employees were hand-delivered survey packets that included five employee surveys and one supervisor survey. The focal employees were asked to fill out an employee survey and ask four coworkers in their work group to fill out employee surveys. They were also asked to have their immediate supervisor fill out the supervisor survey. Respondents were assured confidentiality of their responses. We included postage paid envelopes in the survey packets so that respondents could return their surveys directly to us. This method, often referred to as the "snowball method" (whereby organizational contacts recruit respondents to complete surveys), is consistent with existing approaches used in the literature (e.g., Grant \& Mayer, 2009; Mayer et al., 2009; Piccolo, Greenbaum, Den Hartog, \& Folger, 2010).

We received a total of 1,423 employee responses out of 1,915 surveys (response rate for employee surveys $=74.3 \%$ ) and 295 supervisor responses out of 383 surveys (response rate for supervisor surveys $=$ 77.0\%). Consistent with prior work (Colquitt, Noe, \& Jackson, 2002; Richardson \& Vandenberg, 2005; Schneider, White, \& Paul, 1998; Tracey $\&$ Tews, 2005), we only included groups with three or more respondents. Thus, our final sample included 288 work groups (overall response rate $=75.2 \%$ ), all of which consisted of three or more employees from the same department in the same organization and those employees' immediate supervisors. The employee respondents were 55.4\% male and 54.7\% Caucasian, $12.8 \%$ Hispanic, and $10.2 \%$ African American. They averaged 30.47 years of age with 2.95 years in their department. The supervisor respondents were $56.9 \%$ male and $62.5 \%$ Caucasian, $8.5 \%$ Hispanic, and $7.2 \%$ African American. They averaged 38.47 years of age with 5.49 years in their department.

The employee survey contained measures of abusive supervisor behavior, hostile climate in the work group, and demographic questions. The supervisor survey contained scales measuring work group interpersonal 
deviance, abusive manager behavior (one level above the supervisors), questions assessing the size of the department and organization in terms of the number of employees, and demographic questions.

\section{Measures}

Abusive manager behavior and abusive supervisor behavior. We measured abusive behavior with Tepper's (2000) 15-item abusive supervision scale. A sample item is "My supervisor puts me down in front of others." Responses for these items were made on a seven-point response scale where $1=$ never to $7=$ always. The supervisors reported on the abusive behavior of their managers (i.e., higher level managers) whereas employees reported on the abusive behavior of their immediate supervisors (i.e., lower level managers). The reliabilities for these scales were .97 for the supervisor respondents and .98 for the employee respondents.

Work group interpersonal deviance. We measured employee interpersonal deviant behavior in the work group using Bennett and Robinson's (2000) seven-item Interpersonal Deviance Scale. Supervisors rated the extent to which employees, as a whole, engaged in various deviant behaviors within the past year on a seven-point response format $(1=$ never, $2=$ once, $3=$ a few times, $4=$ several times, $5=$ monthly, $6=$ weekly, $7=$ daily). Sample behaviors included in the scale were making fun of someone at work and acting rudely toward someone at work. The reliability for this scale was .93 .

Hostile climate. We measured hostile climate with five items adapted from Buss and Perry's (1992) Aggression Questionnaire. We altered the scale slightly to assess general/common levels of hostile climate in the work group by assessing what people in the work group "would do" and how they commonly feel. Consistent with prior work on climate, we asked respondents to focus on the work group as a whole as opposed to their own behavior. The items include the stem, "Employees in my work group..." followed by five statements that include, "often feel eaten up with jealousy," "often feel bitter about things," "often talk about each other behind their backs," "have to be suspicious of overly friendly strangers," and "wonder what others want if they are especially nice." The response scale for these items was $1=$ strongly disagree to $7=$ strongly agree. The reliability for this scale was .93 .

Control variables. We included control variables that have been established as potentially important in the context of abusive supervision (e.g., Hoobler \& Brass, 2006). Consistent with prior research (e.g., Aryee et al., 2007; Hoobler \& Brass, 2006), we controlled for supervisors' age, gender, and tenure with their work group and employees' age, gender, and tenure with their work group. Supervisors' and employees' age and 
gender were included as control variables because research on workplace aggression has found that younger adults (those in their late teens to mid-twenties) engage in workplace aggression more frequently than their older counterparts (e.g., Baron, Neuman, \& Geddes, 1999). Furthermore, we controlled for gender because studies have found that females tend to engage in workplace aggression against others less frequently than males (e.g., Baron et al., 1999). Finally, supervisors' and employees' tenure with the work group was included because previous research has demonstrated that it is related to work group deviance (e.g., Robinson \& O'Leary-Kelly, 1998).

\section{Data Aggregation}

We generated the abusive manager behavior, abusive supervisor behavior, and hostile climate measures by aggregating employee ratings to the group level. All constructs in the model are at the workgroup level of analysis. To justify aggregation, we assessed the degree of department employee agreement regarding abusive supervisor behavior and hostile climate by calculating the $r_{w g}$ statistic (George \& James, 1993). The $r_{w g}$ statistic is used to determine interrater agreement. The median $r_{\mathrm{wg}}$ statistic for abusive supervisor behavior was .79 and the median $r_{w g}$ statistic for hostile climate was .72. Although considerable debate exists regarding the adequate "cutoff" for $r_{\mathrm{wg}}$ values (see Lance, Butts, \& Michels, 2006 for a useful review), these values are greater than the generally accepted .70 value.

In addition, we computed intraclass correlations (ICCs) to determine the reliability of the abusive supervisor behavior and hostile climate measures (Bliese, 2000). We used the ICC(1) to examine the degree of variability in responses at the individual level that is attributed to being part of the group. The ICC(1) for abusive supervisor behavior was .28, $F(288,1108)=2.94, p<.001$ and for hostile climate was .34, $F(288,1108)=3.53, p<.001$. We used the ICC(2) coefficient to examine the reliability of the group means. The ICC(2) for abusive supervisor behavior was .66 and for hostile climate was .72. These aggregation statistics provide strong support for aggregating to the workgroup level (Bliese, 2000).

\section{Data Analyses}

Tests of mediation. Hypothesis 3 proposes a mediation model in which abusive manager behavior is related to work group interpersonal deviance through abusive supervisor behavior. Although historically Baron and Kenny's (1986) multistep approach to testing mediation has been 
widely used, some scholars have identified limitations of this approach (e.g., MacKinnon, Lockwood, Hoffman, West, \& Sheets, 2002). Baron and Kenny's approach suggests that a significant relationship between the predictor and dependent variables is necessary for mediation to be inferred. However, methodologists have suggested that as mediating effects become more complex, the magnitude of the relationship between the predictor and dependent variables gets smaller because the effect of the predictor on the dependent variable is "(a) transmitted through additional links in a causal chain, (b) affected by competing causes, and (c) affected by random factors" (Shrout \& Bolger, 2002, p. 429). Therefore, the necessity of demonstrating a significant relationship between the predictor and dependent variables has been called into question (MacKinnon, Krull, \& Lockwood, 2000; Shrout \& Bolger, 2002). In line with this contention, Kenny, Kashy, and Bolger (1998) updated Baron and Kenny's approach and suggested that finding a significant relationship between the predictor and dependent variables is not necessary for establishing mediation. In addition, Shrout and Bolger argue that if the mediated process is theoretically distal, it may not be necessary to first test the relationship between the predictor and the dependent variable.

Hence, it has been argued that mediational analyses should be based on significance tests of the indirect effect of the predictor on the dependent variable (e.g., the Sobel [1982] test), which are considered to more directly address mediation and, therefore, better than Baron and Kenny's (1986) approach (Preacher \& Hayes, 2004). Because the Sobel test assumes that the indirect effect of the predictor on the dependent variable is normally distributed, the use of bootstrapped confidence intervals is also recommended (Edwards \& Lambert, 2007). These confidence intervals make it possible to avoid power problems with nonnormal sampling distributions of an indirect effect (MacKinnon, Lockwood, \& Williams, 2004).

Consistent with these arguments, we tested our hypotheses with a method described by Preacher and Hayes (2004). Their method uses an SPSS macro and incorporates the normal theory approach (i.e., the Sobel test), a bootstrap approach, and Baron and Kenny's (1986) approach to estimate the indirect effects of the predictor on the dependent variable. Our theoretical model examines the effect of abusive manager behavior (i.e., abuse by managers at the upper levels of the organization) on deviant behavior by lower level employees. Thus, abusive manager behavior is both theoretically and hierarchically distal from work group interpersonal deviance. As such, we followed Shrout and Bolger's (2002) recommendations and examined the indirect effect of abusive manager behavior on work group interpersonal deviance through abusive supervisor behavior without testing for the relationship between abusive manager behavior and deviance. 
Tests of moderated mediation. Hypothesis 4(a) predicts that hostile climate moderates the relationship between abusive supervisor behavior and work group interpersonal deviance, and Hypothesis 4(b) suggests hostile climate will moderate the indirect effect of abusive manager behavior on work group interpersonal deviance through abusive supervisor behavior. Thus, Hypothesis 4(b) involves moderated mediation and conditional indirect effects, in which the strength of the hypothesized indirect effect is conditional on the value of the moderator (Preacher, Rucker, \& Hayes, 2007). To test these hypotheses, we utilized an SPSS macro created by Preacher et al., (2007) to run regression equations to estimate mediator variable and dependent variable models. The mediator model was a regression equation that predicted the mediator (abusive supervisor behavior) from the independent variable (abusive manager behavior). The dependent variable model was a regression model that predicted the dependent variable (work group interpersonal deviance) from the independent variable (abusive manager behavior), the mediator (abusive supervisor behavior), the moderator (hostile climate), and the interaction of the moderator and the independent variable. These equations also included the control variables (e.g., supervisor and employee age, gender, and tenure with their department).

\section{Results}

\section{Measurement Model Results}

Before testing our hypotheses, we examined the distinctiveness of the study variables. We conducted confirmatory factor analyses (CFA) with maximum likelihood estimation in LISREL 8.72 (Jöreskog \& Sörbom, 1993). The measurement model consisted of four factors: abusive manager behavior, abusive supervisor behavior, hostile climate, and work group interpersonal deviance. The results indicated the four-factor model provided a good fit to the data $\left(\chi^{2}(129)=419.52, p<.001 ; \mathrm{CFI}=.96\right.$; RMSEA $=.09)$. We compared the four-factor model to a three-factor $\left(\chi^{2}(132)=1315.70, p<.001 ; \mathrm{CFI}=.85 ; \mathrm{RMSEA}=.22\right)$, two-factor $\left(\chi^{2}(134)=2313.37, p<.001 ; \mathrm{CFI}=.72 ; \mathrm{RMSEA}=.27\right)$, and singlefactor model $\left(\chi^{2}(135)=2978.59, p<.001\right.$; CFI $=.63$; RMSEA $=$ .32). A change in $\chi^{2}$ test indicated the four-factor model produced a significant improvement in chi-squares over the three-factor model $\left(\Delta \chi^{2}(3)=896.18, p<.001\right)$, two-factor model $\left(\Delta \chi^{2}(5)=1893.85\right.$, $p<.001)$, and single-factor model $\left(\Delta \chi^{2}(6)=2559.07, p<.001\right)$.

In addition, we acknowledge that the concepts of hostile climate and work group interpersonal deviance may have some conceptual overlap. Therefore, to empirically determine the distinctiveness of these constructs, 
we conducted CFA to test a measurement model that consisted of only two latent factors: hostile climate and work group interpersonal deviance. The results indicated the two-factor model provided a good fit to the data $\left(\chi^{2}(53)=273.11, p<.001 ; \mathrm{CFI}=.95\right.$; RMSEA $=.13$; SRMR $=$ $.04)$. We then compared this model to a single-factor $\left(\chi^{2}(540)=1117.65\right.$, $p<.001 ; \mathrm{CFI}=.75 ; \mathrm{RMSEA}=.31 ; \mathrm{SRMR}=.21)$. A change in $\chi^{2}$ test indicated the two-factor model produced a significant improvement in chi-squares over the single-factor model $\left(\Delta \chi^{2}(1)=844.54, p<.001\right)$. Results of our analyses revealed that the single-factor model did not fit the data well.

\section{Descriptive Statistics}

The means, standard deviations, and intercorrelations among the key variables are presented in Table 1. Correlations among the study variables revealed that abusive manager behavior was positively related to abusive supervisor behavior $(r=.36, p<.05)$, and abusive supervisor behavior was positively related to work group interpersonal deviance $(r=.31$, $p<.05)$.

\section{Hypotheses Tests}

The results for Hypotheses 1, 2, and 3 are presented in Table 2. Consistent with Hypotheses 1 and 2, abusive manager behavior was positively related to abusive supervisor behavior $(\beta=.22, t=5.69, p<.05)$, and abusive supervisor behavior was positively related to work group interpersonal deviance $(\beta=.27, t=2.10, p<.05)$. In addition, in support of Hypothesis 3, abusive manager behavior was found to have an indirect effect on work group interpersonal deviance through abusive supervisor behavior (.10). We also tested the indirect effect with the Sobel test and by calculating a bootstrapped $95 \%$ confidence interval. The Sobel test revealed that the indirect effect was significant $(z=2.77, p<.05)$. This finding was confirmed by the bootstrap results, which demonstrated a bootstrapped $95 \%$ confidence interval around the indirect effect that did not contain zero $(.03, .18)$.

The results for Hypotheses 4(a) and (b) are presented in Table 3. In support of Hypothesis 4(a), results revealed that hostile climate moderated the relationship between abusive supervisor behavior and work group interpersonal deviance $(\beta=.48, t=2.91, p<.05)$. As predicted, the relationship between abusive supervisor behavior and work group interpersonal deviance was stronger when hostile climate was higher.

We also examined the conditional indirect effect of abusive manager behavior on work group interpersonal deviance through abusive supervisor 


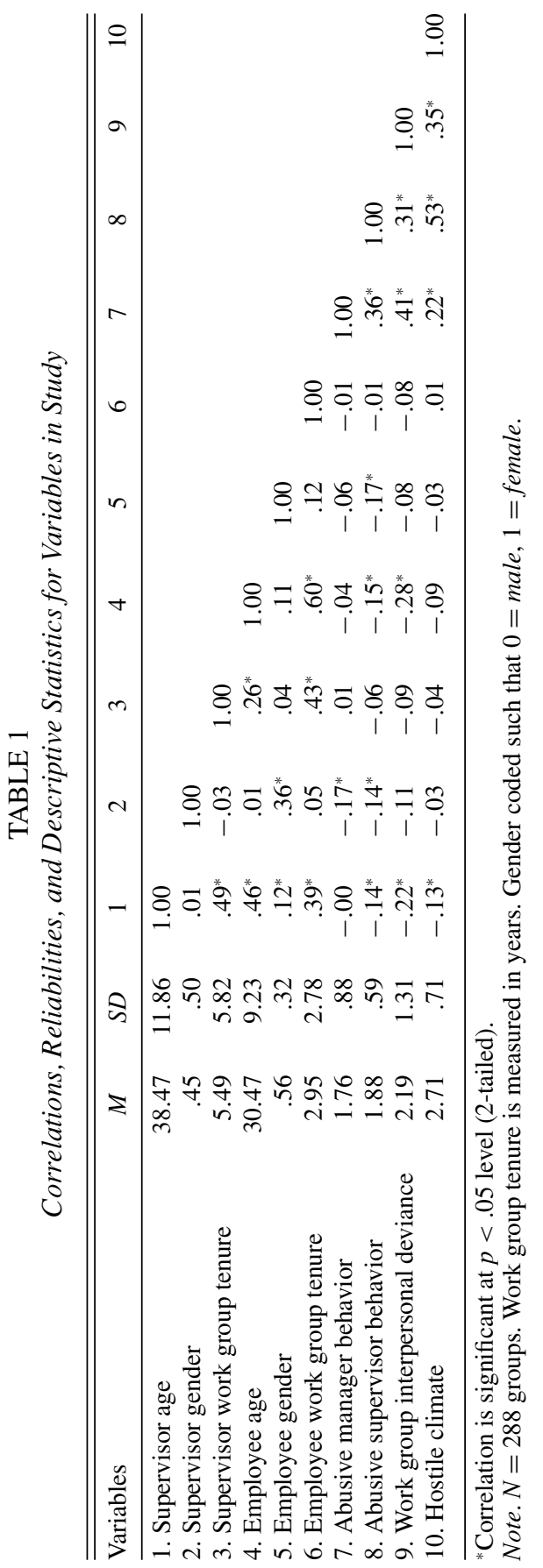


TABLE 2

Regression Results for Simple Mediation

\begin{tabular}{|c|c|c|c|c|}
\hline Variable & $\beta$ & $S E$ & $t$ & $p$ \\
\hline \multicolumn{5}{|c|}{ Partial effect of control variables on interpersonal deviance } \\
\hline Supervisor age & -.01 & .01 & -1.75 & .08 \\
\hline Supervisor sex & -.14 & .15 & -.97 & .33 \\
\hline Supervisor work group tenure & -.00 & .01 & -.31 & .75 \\
\hline Employee age & -.03 & .01 & $-3.38^{*}$ & $.00^{*}$ \\
\hline Employee sex & .02 & .23 & .07 & .94 \\
\hline Employee work group tenure & .07 & .03 & 1.87 & .06 \\
\hline $\begin{array}{l}\text { Interpersonal deviance regressed } \\
\text { on abusive manager behavior }\end{array}$ & $.53^{*}$ & .08 & $6.60^{*}$ & $.00^{*}$ \\
\hline $\begin{array}{l}\text { Abusive supervisor behavior } \\
\text { regressed on abusive manager } \\
\text { behavior }\end{array}$ & $.22^{*}$ & .04 & $5.69^{*}$ & $.00^{*}$ \\
\hline $\begin{array}{l}\text { Interpersonal deviance regressed } \\
\text { on abusive supervisor behavior } \\
\text { controlling for abusive manager } \\
\text { behavior }\end{array}$ & $.27^{*}$ & .13 & $2.10^{*}$ & $.04^{*}$ \\
\hline $\begin{array}{l}\text { Interpersonal deviance regressed } \\
\text { on abusive manager behavior } \\
\text { controlling for abusive } \\
\text { supervisor behavior }\end{array}$ & $.47^{*}$ & .08 & $5.56^{*}$ & $.00^{*}$ \\
\hline $\begin{array}{l}\text { Indirect effect and significance } \\
\text { using normal distribution }\end{array}$ & Value & $S E$ & $z$ & $P$ \\
\hline Sobel & .10 & .03 & 2.77 & .00 \\
\hline $\begin{array}{l}\text { Bootstrap results for indirect } \\
\text { effects }\end{array}$ & $M$ & $S E$ & 95\% CI LL & $95 \%$ CI UL \\
\hline Effect & .10 & .04 & .03 & .18 \\
\hline
\end{tabular}

Note. $N=288$ groups. ${ }^{*} p<.05$. Unstandardized regression coefficients are reported. Bootstrap sample size $=1000 ; \mathrm{LL}=$ lower limit; $\mathrm{CI}=$ confidence interval; $\mathrm{UL}=$ upper limit.

behavior at three values of hostile climate: the mean (2.73), one standard deviation below the mean (2.04), and one standard deviation above the mean (3.42). One of the three conditional indirect effects, that which was one standard deviation below the mean, was marginally significantly different from zero $(p=.08)$, whereas the other two values were not significantly different from zero (see Table 4).

In addition to computing conditional indirect effects at these three values of the moderator, Preacher and colleagues' (2007) method for testing moderated mediation also computes conditional indirect effects at various values of the moderator. This allows for the identification of values of hostile climate for which the conditional indirect effect was statistically significant. Results indicated that the conditional indirect effect was 
TABLE 3

Regression Results for Conditional Indirect Effect

\begin{tabular}{|c|c|c|c|c|}
\hline Predictor & $\beta$ & $S E$ & $T$ & $p$ \\
\hline \multicolumn{5}{|l|}{$\begin{array}{l}\text { Abusive supervisor behavior Model } \\
\text { (mediator variable Model) }\end{array}$} \\
\hline Constant & $2.07^{*}$ & .16 & $12.96^{*}$ & $.00^{*}$ \\
\hline Supervisor age & -.00 & .00 & -1.32 & .19 \\
\hline Supervisor gender & -.03 & .07 & -.37 & .71 \\
\hline Supervisor work group tenure & -.00 & .01 & -.17 & .86 \\
\hline Employee age & $-.01^{*}$ & .00 & $-2.63^{*}$ & $.01^{*}$ \\
\hline Employee gender & $-.26^{*}$ & .11 & $-2.31^{*}$ & $.02^{*}$ \\
\hline Employee work group tenure & $.04^{*}$ & .02 & $2.71^{*}$ & $.01^{*}$ \\
\hline Abusive manager behavior & $.22^{*}$ & .04 & $5.86^{*}$ & $.00^{*}$ \\
\hline \multicolumn{5}{|l|}{$\begin{array}{l}\text { Work group interpersonal deviance } \\
\text { model (dependent variable model) }\end{array}$} \\
\hline Constant & $4.22^{*}$ & .97 & $4.34^{*}$ & $.00^{*}$ \\
\hline Supervisor age & -.01 & .01 & -1.83 & .07 \\
\hline Supervisor gender & -.17 & .14 & -1.17 & .24 \\
\hline Supervisor work group tenure & -.00 & .01 & -.22 & .83 \\
\hline Employee age & $-.03^{*}$ & .01 & $-3.42^{*}$ & $.00^{*}$ \\
\hline Employee gender & -.08 & .23 & -.36 & .72 \\
\hline Employee work group tenure & .07 & .03 & 1.93 & .05 \\
\hline Abusive manager behavior & $.44^{*}$ & .08 & $5.40^{*}$ & $.00^{*}$ \\
\hline Abusive supervisor behavior & $-1.42^{*}$ & .51 & $-2.76^{*}$ & $.01^{*}$ \\
\hline Hostile climate & -.48 & .31 & -1.57 & .12 \\
\hline $\begin{array}{l}\text { Abusive supervisor behavior } \times \\
\text { hostile climate }\end{array}$ & $.48^{*}$ & .17 & $2.91^{*}$ & $.00^{*}$ \\
\hline Model summaries & $R^{2}$ & $\Delta R^{2}$ & $F$ & $P$ \\
\hline $\begin{array}{l}\text { Work group interpersonal deviance } \\
\text { regressed on abusive supervisor } \\
\text { behavior }\end{array}$ & .16 & - & $17.36^{*}$ & $.00^{*}$ \\
\hline $\begin{array}{l}\text { Work group interpersonal deviance } \\
\text { regressed on abusive supervisor } \\
\text { behavior } \times \text { hostile climate }\end{array}$ & .18 & $.02^{*}$ & $4.96^{*}$ & $.03^{*}$ \\
\hline $\begin{array}{l}\text { Work group interpersonal deviance } \\
\text { model }\end{array}$ & .23 & $.05^{*}$ & $13.09^{*}$ & $.00^{*}$ \\
\hline \multirow{2}{*}{$\begin{array}{l}\text { Bootstrap results for conditional } \\
\text { indirect effect }\end{array}$} & Value & $S E$ & $95 \%$ CI LL & $95 \%$ CI UL \\
\hline & .11 & .06 & .01 & .24 \\
\hline
\end{tabular}

significant at $p=.05$ for any value of hostile climate less than 2.01 and any value greater than 3.85 . These results are shown in Table 4 . These findings indicate that the conditional indirect effect was significant when hostile climate was high (i.e., greater than one standard deviation above the mean) as well as low (i.e., greater than one standard deviation below the mean). These effects are shown in Figure 2. The figure illustrates the relation- 
TABLE 4

Conditional Indirect Effects at Various Values of the Moderator (Hostile Climate)

\begin{tabular}{lcrrr}
\hline \hline $\begin{array}{l}\text { Conditional indirect effects at } \\
M \pm 1 S D\end{array}$ & $\begin{array}{c}\text { Boot indirect } \\
\text { effect }\end{array}$ & Boot $S E$ & Boot $z$ & Boot $p$ \\
\hline$-1 S D(2.04)$ & -.09 & .05 & -1.73 & .08 \\
$M(2.73)$ & -.02 & .03 & -.47 & .64 \\
$+1 S D(3.42)$ & .05 & .04 & 1.50 & .13 \\
Conditional indirect effects at $^{\text {range of values }}{ }^{a}$ & Boot indirect effect & Boot $S E$ & Boot $z$ & Boot $p$ \\
1.90 & & & & \\
2.01 & -.11 & .06 & -2.04 & $.04^{*}$ \\
2.07 & -.10 & .05 & -1.96 & .05 \\
2.42 & -.08 & .05 & -1.70 & .09 \\
2.76 & -.05 & .04 & -1.22 & .22 \\
3.10 & -.01 & .03 & -.39 & .70 \\
3.45 & .02 & .03 & .70 & .48 \\
3.62 & .06 & .04 & 1.55 & .12 \\
3.79 & .07 & .04 & 1.82 & .07 \\
4.14 & .09 & .05 & 2.01 & .04 \\
4.31 & .13 & .06 & 2.23 & $.03^{*}$ \\
4.48 & .14 & .06 & 2.26 & $.02^{*}$ \\
\hline
\end{tabular}

Note. $n=288$ groups. ${ }^{*} p<.05$. Unstandardized regression coefficients are reported. Bootstrap sample size $=5000 .{ }^{a}$ Range of values represents an abbreviated version of the output provided by the SPSS macro.

ship between abusive supervisor behavior and work group interpersonal deviance at five levels of the moderator (the mean, one standard deviation above and below the mean, and two standard deviations above and below the mean). As you can see in the figure, the positive relationship between abusive supervisor behavior and workgroup interpersonal deviance is strengthened when hostile climate is two standard deviations above the mean and reversed when hostile climate is two standard deviations below the mean.

In sum, in support of Hypothesis 4(b), these results demonstrate that abusive supervisor behavior functions as a mediator and that the indirect effect of abusive manager behavior on work group interpersonal deviance is moderated by hostile climate. Our results support our predictions in that they indicate that the conditional indirect effect was significant when hostile climate was high, but also extend our predictions by indicating a buffering effect of low-hostile climate. In particular, our results demonstrate that lower levels of climate mitigated (and actually reversed) the positive effects of abusive supervisor behavior on work group interpersonal deviance. 


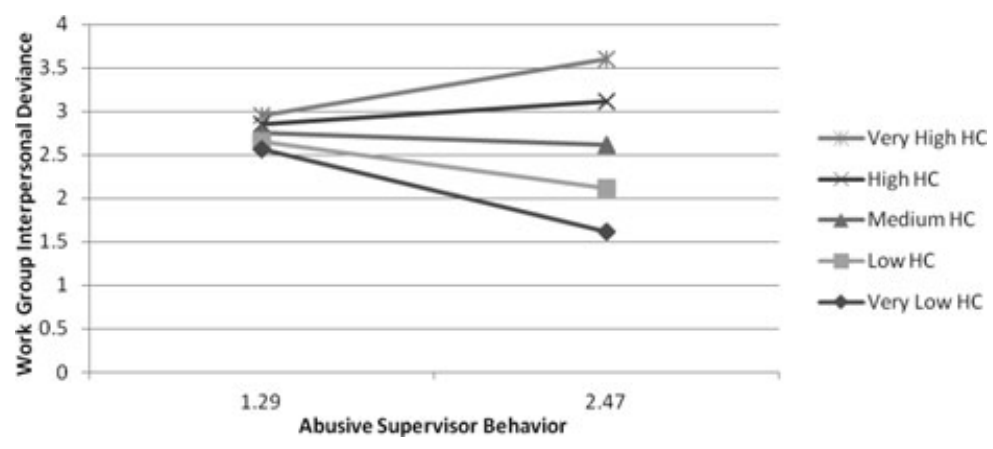

Figure 2: Plot of the Indirect Effect of Abusive Manager Behavior on Work Group Interpersonal Deviance Through Abusive Supervisor Behavior at Various Levels of the Moderator (Hostile Climate).

Note. $\mathrm{HC}=$ Hostile Climate.

\section{Discussion}

In this paper, we developed and tested a model of the trickle-down effects of abusive manager behavior on direct reports (i.e., supervisors) and on employees who hold positions two hierarchical levels below the managers. Our model predicted employees would be negatively impacted by abusive manager behavior through their direct supervisor's abusive behavior. We also examined the moderating effect of hostile climate. We found support for our trickle-down model. Abusive manager behavior was positively associated with abusive supervisor behavior, and abusive supervisor behavior was positively associated with work group interpersonal deviance. In addition, higher levels of hostile climate strengthened the positive relationship between abusive supervisor behavior and work group interpersonal deviance stronger, whereas lower levels of climate buffered and actually reversed the effects of abusive supervisor behavior on workgroup deviance. Thus, we not only found support for our trickledown model of abusive supervision, but we also found that the climate of the work environment played a role in the trickle-down effect.

There are a number of strengths of our research that should be highlighted. First, although prior work on abusive supervision has typically examined only supervisor-subordinate dyads, we extended this work by examining the role of abusive manager behavior. We examined the effects of abusive supervision at higher levels of the organization and found that the detrimental effects of abuse can extend beyond the supervisorsubordinate relationship. Consistent with calls for studying aggression as a system of social interactions (e.g., Andersson \& Pearson, 1999), we tested a trickle-down model linking abusive manager behavior to employees' 
deviant behavior through abusive supervisor behavior. We drew on social learning theory to suggest that abusive behavior in organizations can flow downward from higher levels of management to lower level employees. Taking a social learning perspective, our results provided support for this trickle-down effect suggesting that abusive behavior at higher levels in the organization is role modeled by those at lower levels (i.e., supervisors and employees).

We also explored a boundary condition of the effects of abusive supervisor behavior-hostile climate. As predicted, we found that hostile climate moderated the relationship between abusive supervisor behavior and workgroup interpersonal deviance. There are several things worth noting about this interaction. First, although this effect size is small, it is comparable to the effect sizes of most interaction terms reported in organizational sciences (Aguinis, Beaty, Boik, \& Pierce, 2005). In addition, given the cost of deviant behaviors in organizations, explaining even $2 \%$ of the variance in these behaviors is practically significant (e.g., Aguinis, Werner, Abbott, Angert, Park, \& Kohlhausen, 2010). Second, we find that the relationship between abusive supervisor behavior and workgroup interpersonal deviance is only significant at quite low and high levels of hostile climate. Indeed, given that the results indicated that the conditional indirect effect was significant at $p=.05$ for any value of hostile climate less than 2.01 and any value greater than 3.85 , it is clear that a hostile climate must be quite low or high to influence the relationship between abusive supervisor behavior and workgroup interpersonal deviance. These findings point to the strong impact of supervisors on employees' behavior-particularly a severe form of behavior such as abusive supervision. Given the powerful effect of abusive supervisor behavior, it is intriguing that we can still find an aspect of the workgroup climate that can strengthen (or even reverse) the influence of abusive supervision. Third, the relationship between abusive supervisor behavior and workgroup interpersonal deviance is actually negative when hostile climate is quite low. Given the powerful and detrimental influence of abusive supervision, we believe this finding is particularly promising in terms of understanding how to combat such deleterious effects of abusive supervisors. One possible explanation for this finding is that, when a hostile climate is quite low, employees get along very well with one another. They are happy for others when they have success, are not bitter, do not speak behind others' backs, and are trusting of others and their motives. In such an environment, employees are likely to care about others' well-being in their work group. When a supervisor is abusive to employees in such a climate, the employees are even less likely to do anything that could provide additional pain to fellow employees. In other words, they are even less likely to "pour salt on the wounds" of their fellow work group employees. 
In reference to the moderating effect of hostile climate, it should be noted that although we predicted that hostile climate will moderate the link between abusive supervisor behavior and work group interpersonal deviance, we did not make a similar prediction for the link between abusive manager behavior and abusive supervisor behavior. Two lines of research support the notion that hostile climate should not moderate both relationships. First, research on social information processing suggests that the extent to which an individual processes and relies on information from his or her social context is influenced by individual difference variables, such as past experience. This research indicates that individuals with higher levels of experience are less likely to look to the social context for cues on how to behave (see Zalesny \& Ford, 1990, for a review). Because supervisors customarily have higher levels of work experience than lower level employees, supervisors may be less reliant on their environment for information regarding behavioral norms than lower level employees. Supervisors will mimic their managers' behaviors but will not need to look to their work environment for cues on whether or not the managers' behaviors should be role modeled.

Second, research on referent selection suggests that lower-level employees are more likely than supervisors to select their peers as referents and look to their work group for cues on what behaviors are appropriate (Oldham, Kulik, Stepina, \& Ambrose, 1986). An individual's selection of a referent is partially driven by the availability of information regarding the similarities between the individual and the referent (Mowday, 1991). Given the pyramid shape of most organizations, employees at lower levels of the organization usually have more access to information about referents within the organization and at the same organizational level (Kulik \& Ambrose, 1991). Furthermore, research on referent selection indicates that individuals prefer referents who are similar to themselves in performance-related attributes (e.g., Wheeler, Koestner, \& Driver, 1982; Zanna, Goethals, \& Hill, 1975) and abilities (e.g., Festinger, 1954), suggesting that employees are likely to use their contemporaries as referents on how to behave. Employees will mimic their supervisors' behaviors but will also look to their work group for cues on the appropriateness of their supervisors' behaviors. Thus, we did not expect hostile climate to impact supervisors' reactions to their managers' behavior in the same manner as they influence employees' reactions to their supervisors.

\section{Theoretical Implications}

The strengths of our research create a number of theoretical and practical implications. Social learning theory provided the theoretical basis for our trickle-down predictions. Although social learning theory has often 
been applied to the modeling of desirable behaviors (Dovidio, Piliavin, Schroeder, \& Penner, 2006), recent studies have only just begun extending the theory to the context of aggressive behavior, as we do here. Consistent with social learning theory, supervisors appear to model the aggressive acts of their managers such that the aggression trickles down, negatively affecting employees' behaviors as well. Our findings suggest that just as supervisors may model their superiors' positive leader behaviors, they may adopt negative leader behaviors as well. Thus, supervisors seem to respond to abusive manager behavior by engaging in aggressive behavior toward their own subordinates.

In addition, based on social learning and social information processing theories, our findings regarding the moderating effect of hostile climate suggest that when work groups were characterized as hostile, employees in the work group more freely engaged in interpersonal deviance in response to their supervisors' abusive behavior. These findings not only lend support to role-modeling theories, such as social learning theory, but also lend support to theories, such as social information processing theory, that suggest that individuals look to those around them to determine what behaviors are normatively appropriate. In line with these theories, our findings suggest that employees pay attention to others in their work context for guidance in determining what behaviors are appropriate at work. In addition, the finding that lower levels of hostile climate buffered and reversed the effects of abusive supervisor behavior on work group deviance contributes to our knowledge in that it indicates that although a work context that supports mimicry of abusive behaviors (e.g., one with high levels of hostile climate) can increase the likelihood that role modeling of abuse will occur, a context that acts in opposition to these abusive behaviors may limit role modeling of such negative behaviors. Our findings for the moderating effect of low-hostile climate further support the notion that individuals look to their work environment when deciding on how to behave. Overall, our results for the moderating effect of climate suggest that aspects of the organizational context can play a significant role in shaping employee behaviors. Recognizing hostile climate as a contextual moderator provides a richer and more complete understanding of the unfolding trickle-down process of abuse.

\section{Practical Implications}

Practically, our findings suggest that dysfunctional behaviors in organizations are not simply the result of a handful of "bad apples" (i.e., individual actors). A "bad apple theory" has been pervasive in the business world in response to destructive behaviors in organizations, such as unethical behavior (Treviño \& Brown, 2004). The first reaction to dysfunctional 
behavior, by the media or the organization affected, is to attempt to punish, and/or remove the perpetrator. The thought is that if the organization can get rid of the "bad apple," all will be well again. Certainly there are "bad apples" that should be identified and removed; however, the results of our study suggest that dysfunctional behaviors in organizations, such as abusive supervision, can extend far beyond the perpetrator. In essence, theories, such as social learning and social information processing theories, and the results of our study support the notion that people are often in part the product of their environment. Thus, in combating dysfunctional actions, such as abusive supervision, organizations may do well to take a more active role in reducing situational factors that may make the trickle down of abuse more likely. Our finding regarding the buffering effect of low-hostile climate suggest that organizations can limit role modeling of abusive behaviors by encouraging a context that does not support hostile behavior. Thus, positive organizational climates should be fostered and encouraged.

Beyond the implications of our findings for organizations as a whole, our results also have direct implications for potential role models at all levels of the organization. In describing social learning theory, many scholars reference parent-child and teacher-student relationships, suggesting that children/students are likely to observe and role model the behaviors of those they look up to and admire (i.e., their parents/teachers; Ormond, 1999). Organizational interpersonal relationships, such as supervisorsubordinate relationships, or even those between coworkers, are similar in many ways. Given that behaviors are often learned by observing others, employees and managers at all levels of the organization should be cognizant of the fact that they may be serving as role models to others and that others at lower levels may be observing and mimicking their behavior. This is especially true when interacting with less experienced or lower level employees, who may be more likely to look to those around them for cues on what behaviors are appropriate. Hence, all organizational members should be encouraged to act as positive role models to others, especially to those employees who may be more receptive or impressionable.

Another practical implication comes from our finding of congruence between group members' perceptions of whether or not their supervisor was abusive. Previous studies have oriented themselves around a model, much like a leader-member exchange (LMX) perspective, that leaders have distinctly positive or negative relationships with each of their followers, that is, that no leader is universally a good or bad leader. However, our $r_{w g}$ and ICC values lend support to the idea that group members had similar perceptions of the degree to which their supervisor was abusive. Practically, this supports the notion that abusive supervisors can be identified and perhaps targeted for coaching, retraining, and/or perhaps 
termination. Subordinate perceptions of them as poor supervisors should send a clear message to organizational decision makers regarding whether or not supervisors are doing a good job. As such, common organizational attitude and satisfaction survey assessments of supervisor satisfaction may be quite helpful in rooting out abusive supervisors.

\section{Limitations and Future Research}

The findings of this study need to be considered in light of its weaknesses. One limitation is that the study was cross-sectional, and thus, we could not determine the direction of causality among the variables. Our theoretical model proposes a trickle-down effect in which abusive behaviors flow downward through organizational hierarchies; however, it is possible that behaviors may flow upward in organizations. The term upward influence has been used to describe instances in which influence flows from lower level subordinates upward into higher levels of the organization (e.g., Yukl \& Falbe, 1990, 1991). Thus, we acknowledge that mimicry of behaviors may flow in the opposite direction than what we describe. Nevertheless, our focus on the trickle-down effect is consistent with the majority of research on leadership, which examines the downward influence of supervisor attitudes and behaviors on attitudinal and behavioral responses of subordinates (e.g., Bass et al., 1987; Mayer et al., 2009; Mitchell \& Ambrose, 2007; Piccolo \& Colquitt, 2006; Tepper, 2000). This research suggests that influence most frequently occurs in a downward fashion. Although we focus on downward influence here, we do believe that future research should examine how the process we describe in this paper may actually flow in the opposite direction. Future research should examine these relationships longitudinally or in a laboratory setting.

A second limitation is that we assessed workgroup interpersonal deviance using supervisor reports. It may be possible that supervisors do not see all of the interpersonal behavior displayed in work groups, and thus employees would be a better judge of interpersonal deviance. However, prior research has demonstrated a positive relationship between employee and supervisor reports of group-level deviance (e.g., Mayer et al., 2009). Still, future research should examine deviant behavior using employee assessments as well.

Measuring workgroup interpersonal deviance from the supervisors' perspective may have also created issues with same source bias. Our results indicated that the correlation between abusive manager behavior and workgroup interpersonal deviance $(r=.41)$ was stronger than the correlation between abusive supervisor behavior and workgroup interpersonal deviance $(r=.31)$. The stronger correlation for the abusive manager 
behavior-deviance relationship may have been a function of the fact that both variables were measured by the same source. However, the stronger correlation may indicate differences in the levels of influence of direct versus indirect leaders. These correlations may also help to explain why abusive supervisor behavior partially mediated the relationship between abusive manager behavior and workgroup interpersonal deviance. It may be that higher level managers influence lower level employees both directly and indirectly through the effect they have on supervisors. Future research should examine these possibilities.

A final potential limitation is our snowball sampling research design, with its associated possibility of sampling bias. Although the procedure has been used successfully in prior research (e.g., Grant \& Mayer, 2009; Mayer, Aquino, Greenbaum, \& Kuenzi, 2012; Mayer et al., 2009; Piccolo et al., 2010), a concern that cannot be ruled out is that putting one focal employee in charge of survey administration at each organization may skew the employee responses obtained. The focal employee may have given surveys to people similar to them or whom they like-those who in general harbor similar attitudes about the group and their supervisor.

The limitations of our research create avenues for future research, and our research motivates future inquiry on the dark side of leadership. For example, although we draw on social learning theory to suggest that organizational members imitate the behaviors of their superiors, we did not measure any role-modeling mechanisms in this trickle-down effect. Future research should examine possible role model mechanisms to confirm that this is in fact the process underlying the trickle-down effect.

In addition, although we believe the trickle-down effect is more likely to occur when the observed behaviors are directed at the observer, it is possible that the trickle-down process may occur even when the abusive behavior is not directed specifically at the subordinate. This notion is interesting on two fronts. First, to our knowledge, research on abusive supervision has only examined the effects of abuse on those who are the targets of the abusive behavior. The effects of the presence of abuse on all organizational members (and even stakeholders outside the organization), regardless of whether or not they are the victims of the abuse, should be examined. Some research on organizational injustice, a concept related to abusive supervision, has examined third-party (i.e., observer) reactions to injustices (e.g., Turillo, Folger, Lavelle, Umphress, \& Gee, 2002; Umphress et al. 2009, unpublished data). Future research should build on this related knowledge to investigate third-party reactions to abusive supervision.

Second, aside from observer reactions, it may be that the presence of generalized abusive managerial behavior creates abusive behavior at all levels of the organization. This is interesting in that it suggests causal 
relationships that we did not propose for this study. Our theoretical model examines a contextual factor, hostile climate, as a moderator of the trickledown effect. However, perhaps, the relationships among the constructs in our theoretical model are more complex than we depicted. Perhaps abusive behaviors at the manager and supervisor levels, deviant behaviors at the employee level, and hostile climate in the work group actually have reciprocal relationships, in that each feeds off of and influences each other. Of course, these contentions are speculative, and future research should attempt to examine these relationships.

Additional future research also stems from the cross-sectional nature of our data. In addition to not permitting us to rule out the possibility of upward influence, and a trickle-up effect, our data also did not allow us to conclude that hostile climate only functions as a moderator in the system of abuse we examine. Because of organizational processes such as socialization and the ASA process, behaviors of managers and supervisors can influence a work group's climate, making hostile climate an outcome of abusive supervision and a possible mediator instead of a moderator. Although we acknowledge that hostile climate in a work group may be influenced by a leader's abusive behaviors, there are two main reasons why we chose to examine the construct as a moderator. First, a strength of our research is the examination of hostile climate as a contextual variable that can influence the trickle-down effect of abuse. Treating hostile climate as a mediator would have taken away this contribution. Second, methodologically, an examination of hostile climate as a mediator would have been problematic. If we had examined climate as a mediator, our theoretical model would have had three links and four variables. However, our data are cross-sectional. Given the limitations of our data in terms of making causal claims, we think a model with two links involving three variables (and a moderator) is more defensible. Nevertheless, although we chose to examine climate as a moderator in our paper, we do believe that longitudinal studies should be conducted to examine the possibility of hostile climate functioning as a mediator.

Additional possibilities for future research stem from the question of what breaks the cycle. ${ }^{2}$ In this study, we predict a trickle-down effect of abuse and examine workgroup hostile climate as a moderator that can strengthen (or reverse) these effects. This then leads to the question of what buffers and/or impedes the effect. The results of our moderating hypotheses partially address this question in that our findings indicate that low-hostile climate seems to mitigate and actually reverse the effects of abusive supervisor behavior on workgroup interpersonal deviance. Nevertheless, this question remains largely unanswered. To provide knowledge

${ }^{2}$ We thank an anonymous reviewer for this suggestion. 
on how to lessen, or even curb, role modeling of abusive behavior, future research should examine both contextual factors as well as individual characteristics of organizational members that may break the role modeling cycle. In terms of contextual factors, research should examine the moderating effects of constructs such as ethical climate (e.g., Wimbush \& Shepard, 1994), justice climate (e.g., Colquitt et al., 2002), or perceptions that abusive behavior will be punished. In addition, followers' characteristics may limit their willingness to imitate their superiors' behaviors, such as high levels of moral identity (e.g., Aquino \& Reed, 2002), Conscientiousness, or Agreeableness.

\section{Conclusion}

In summary, the results of our study indicate that abusive supervision has effects beyond the supervisor-subordinate dyad. However, if the work group has a low-hostile climate, the negative effects of abusive supervisor behavior can be neutralized (and even reversed), and the spiral of negative workplace behavior is thwarted. Based on these results, we encourage researchers and practitioners alike to continue to broaden their understanding of the far-reaching implications of abusive supervision.

\section{REFERENCES}

Aguinis H, Beaty JC, Boik RJ, Pierce CA. (2005). Effect size and power in assessing moderating effects of categorical variables using multiple regression: A 30-year review. Journal of Applied Psychology, 90, 94-107.

Aguinis H, Werner S, Abott JL, Angert C, Park JH, Kohlhausen D. (2010). Customer-centric science: Reporting significant research results with rigor, relevance, and practical impact in mind. Organizational Research Methods, 13, 515-539.

Andersson LM, Pearson CM. (1999). Tit for tat? The spiraling effect of incivility in the workplace. Academy of Management Review, 24, 452-471.

Aquino K, Reed A. (2002). The self-importance of moral identity. Journal of Personality and Social Psychology, 83, 1423-1440.

Aryee S, Chen ZX, Sun L, Debrah YA. (2007). Antecedents and outcomes of abusive supervision: Test of a trickle-down model. Journal of Applied Psychology, 92, 191201.

Ashkanasy NM, Nicholson GJ. (2003). Climate of fear in organizational settings: Construct definition, measurement and a test of theory. Australian Journal of Psychology, 55, 24-29.

Bandura A. (1977). Social learning theory. Englewood Cliffs, NJ: Prentice Hall.

Bandura A. (1986). Social foundations of thought and action: A social cognitive theory. Englewood Cliffs, NJ: Prentice-Hall.

Baron RM, Kenny DA. (1986). The moderator-mediator variable distinction in social psychological research: Conceptual, strategic, and statistical considerations. Journal of Personality and Social Psychology, 51, 1173-1182. 
Baron RA, Neuman JH, Geddes D. (1999). Social and personal determinants of workplace aggression: Evidence for the impact of perceived injustice and the type A behavior pattern. Aggressive Behavior, 25, 281-296.

Bass BM, Waldman DA, Avolio BJ, Bebb M. (1987). Transformational leadership and the falling dominoes effect. Group \& Organization Management, 12, 73-87.

Bennett R, Robinson S. (2000). Development of a measure of workplace deviance. Journal of Applied Psychology, 85, 349-360.

Berscheid E, Graziano W, Monson T, Derner M. (1976). Outcome dependency: Attention, attribution, and attraction. Journal of Personality and Social Psychology, 34, 978989.

Bliese PD. (2000). Within-group agreement, non-independence, and reliability: Implications for data aggregation and analyses. In Klein KJ, Kozlowski SWJ (Eds.), Multilevel theory, research, and methods in organizations: Foundations, extensions, and new directions (pp. 349-381). San Francisco, CA: Jossey-Bass.

Brown ME, Treviño LK. (2006). Socialized charismatic leadership, values congruence, and deviance in work groups. Journal of Applied Psychology, 91, 954-962.

Brown ME, Treviño LK, Harrison DA. (2005). Ethical leadership: A social learning perspective for construct development and testing. Organizational Behavior \& Human Decision Processes, 97, 117-134.

Buss AH, Perry M. (1992). The aggression questionnaire. Journal of Personality and Social Psychology, 63, 452-459.

Carr JZ, Schmidt AM, Ford JK, DeShon RP. (2003). Climate perceptions matter: A metaanalytic path analysis relating molar climate, cognitive and affective states, and individual level work outcomes. Journal of Applied Psychology, 88, 605-619.

Chen Z, Lam W, Zhong JA. (2007). Leader-member exchange and member performance: A new look at individual-level negative feedback-seeking behavior and team-level empowerment climate. Journal of Applied Psychology, 92, 202-212.

Choi JN, Price RH, Vinokur AD. (2003). Self-efficacy changes in groups: Effects of diversity, leadership and group climate. Journal of Organizational Behavior, 24, $357-371$.

Colquitt J, Noe R, Jackson C. (2002). Justice in teams: Antecedents and consequences of procedural justice climate. PERSONNEL PSYCHOLOGY, 55, 83-109.

De Rivera J. (1992). Emotional climate: Social structure and emotional dynamics. In Strongman KT (Ed.), International review of studies on emotions (pp. 197-218). Chichester, UK: John Wiley \& Sons.

Dovidio JF, Piliavin JA, Schroeder DA, Penner L. (2006). The social psychology of prosocial behavior. Mahwah, NJ: Erlbaum.

Dupre' KE, Barling J. (2006). Predicting and preventing supervisory workplace aggression. Journal of Occupational Health Psychology, 11, 13-26.

Edwards JR, Lambert LS. (2007). Methods for integrating moderation and mediation: A general analytical framework using moderated path analysis. Psychological Reports, $12,1-22$.

Erdogan B, Bauer TN. (2010). Differentiated leader-member exchanges: The buffering role of justice climate. Journal of Applied Psychology, 95, 1104-1120.

Festinger L. (1954). A theory of social comparison processes. Human Relations, 7, 117140.

French JRP Jr., Raven B. (1959). The bases of social power. In Cartwright D (Ed.), Studies in social power (pp. 150-167). Ann Arbor, MI: University of Michigan, Institute of Social Research.

Goldstein JH. (1986). Aggression and crimes of violence, (2nd ed.). New York, NY: Oxford University Press. 
Grant AM, Mayer DM. (2009). Good soldiers and good actors: Prosocial and impression management motives as interactive predictors of affiliative citizenship behaviors. Journal of Applied Psychology, 94, 900-912.

Hofmann DA, Morgeson FP, Gerras SJ. (2003). Climate as a moderator of the relationship between leader-member exchange and content specific citizenship: Safety climate as an exemplar. Journal of Applied Psychology, 88, 170-178.

Hoobler JM, Brass DJ. (2006). Abusive supervision and family undermining as displaced aggression. Journal of Applied Psychology, 91, 1125-1133.

Hui CH, Chiu WCK, Yu PLH, Cheng K, Tse HHM. (2007). The effects of service climate and the effective leadership behavior of supervisors on frontline employees service quality: A multi-level analysis. Journal of Occupational and Organizational Psychology, 80, 151-172.

Inness M, Barling J, Turner N. (2005). Understanding supervisor-targeted aggression: A within-person, between-jobs design. Journal of Applied Psychology, 90, 731-739.

Jöreskog K, Sörbom D. (1993). LISREL 8: Structural equation modeling with the SIMPLIS command language. Lincolnwood, IL: Scientific Software International.

Kenny DA, Kashy DA, Bolger N. (1998). Data analysis in social psychology. In Gilbert DAT, Fiske ST, Lindzey G (Eds.), Handbook of Social Psychology (pp. 233-265). New York, NY: Oxford University Press.

Kuenzi M, Schminke M. (2009). A fragmented literature? A review, critique, and proposed research agenda of the work climate literature. Journal of Management, 35, 634-717.

Kulik CT, Ambrose ML. (1991). Personal and situational determinants of referent choice. Academy of Management Review, 17, 212-237.

Lance CE, Butts MM, Michels LC. (2006). The sources of four commonly reported cutoff criteria: What did they really say? Organizational Research Methods, 9, 202-220.

Liao H, Chuang A. (2007). Transforming service employees and climate: A multilevel multi-source examination of transformational leadership in building long-term service relationships. Journal of Applied Psychology, 92, 1006-1019.

MacKinnon DP, Krull JL, Lockwood CM. (2000). Equivalence of the mediation, confounding, and suppression effect. Prevention Science, 1, 173-181.

MacKinnon CM, Lockwood CM, Hoffman JM, West SG, Sheets V. (2002). A comparison of methods to test mediation and other intervening variable effects. Psychological Methods, 7, 83-104.

MacKinnon DP, Lockwood CM, Williams J. (2004). Confidence limits for the indirect effect: Distribution of the product and resampling methods. Multivariate Behavioral Research, 39, 99-128.

Mayer DM, Aquino K, Greenbaum RL, Kuenzi M. (2012). Who displays ethical leadership, and why does it matter? An examination of antecedents and consequences of ethical leadership. Academy of Management Journal, 55, 151-171.

Mayer DM, Kuenzi M, Greenbaum RL, Bardes M, Salvador R. (2009). How low does ethical leadership flow? Test of a trickle down model. Organizational Behavior and Human Decision Processes, 108, 1-13.

Mitchell MS, Ambrose ML. (2007). Abusive supervision and workplace deviance and the moderating effects of negative reciprocity beliefs. Journal of Applied Psychology, $92,1159-1168$.

Mowday RT. (1991). Equity theory predictions of behavior in organizations. In Steers R, Porter L. (Eds.), Motivation and work behavior (5th ed., pp. 111-131). New York, NY: McGraw-Hill.

O'Leary-Kelly AM, Griffin RW, Glew DJ. (1996). Organization-motivated aggression: A research framework. Academy of Management Review, 21, 225-253. 
Oldham GR, Kulik CT, Stepina LP, Ambrose ML. (1986). Relations between situational factors and the comparative referents used by employees. Academy of Management Journal, 29, 599-608.

Ormond JE. (1999). Human learning (3rd ed.). Upper Saddle River, NJ: Prentice-Hall.

Ostroff C. (1993). The effects of climate and personal influences on individual behavior and attitudes in organizations. Organizational Behavior and Human Decision Processes, 56, 56-90.

Piccolo RF, Colquitt JA. (2006). Transformational leadership and job behaviors: The mediating role of core job characteristics. Academy of Management Journal, 49, 327-340.

Piccolo RF, Greenbaum RL, Den Hartog D, Folger R. (2010). The relationship between ethical leadership and core job characteristics. Journal of Organizational Behavior, 31, 259-278.

Preacher CJ, Hayes AF. (2004). SPSS and SAS procedures for estimating indirect effects in simple mediation models. Behavior Research Methods, 36, 717-731.

Preacher KJ, Rucker DD, Hayes AF. (2007). Addressing moderated mediation hypotheses: Theory, methods, and prescriptions. Multivariate Behavioral Research, 42, 185-227.

Richardson H, Vandenberg R. (2005). Integrating managerial perceptions and transformational leadership into a work-unit level model of employee involvement. Journal of Organizational Behavior, 26, 561-589.

Robinson SL, Bennett RJ. (1995). A typology of deviant workplace behaviors: A multidimensional scaling study. Academy of Management Journal, 38, 555-572.

Robinson SL, O'Leary-Kelly AM. (1998). Monkey see, monkey do: The influence of work groups on the antisocial behavior of employees. Academy of Management Journal, $41,658-672$.

Salancik GR, Pfeffer J. (1978). A social information processing approach to job attitudes and task design. Administrative Science Quarterly, 23, 224-253.

Schneider B. (1987). The people make the place. Personnel Psychology, 40, 437-453.

Schneider B, Ehrhart MG, Macey WH. (2011). Perspectives on organizational climate and culture. In Zedeck S (Ed.), Handbook of industrial and organizational psychology: Building and developing the organization. (Vol. 1, pp. 373-414). Washington, DC: American Psychological Association.

Schneider B, White SS, Paul MC. (1998). Linking service climate and customer perceptions of service quality: Tests of a causal model. Journal of Applied Psychology, 83, 150 163.

Shamir B. (1995). Social distance and charisma: Theoretical notes and an exploratory study. Leadership Quarterly, 6, 19-47.

Shrout PE, Bolger N. (2002). Mediation in experimental and nonexperimental studies: New procedures and recommendations. Psychological Methods, 7, 422-445.

Sobel ME. (1982). Asymptotic confidence intervals for indirect effects in structural equation models. Sociological Methodology, 13, 290-312.

Tepper BJ. (2000). Consequences of abusive supervision. Academy of Management Journal, 43, 178-190.

Tepper BJ. (2007). Abusive supervision in work organizations: Review, synthesis, and research agenda. Journal of Management, 33, 261-289.

Tepper BJ, Duffy MK, Henle CA, Lambert LS. (2006). Procedural injustice, victim precipitation and abusive supervision. Personnel Psychology, 59, 101-123.

Tepper BJ, Henle CA, Lambert LS, Giacalone RA, Duffy MK. (2008). Abusive supervision and subordinates' organization deviance. Journal of Applied Psychology, 93(4), 721-732.

Tepper BJ, Taylor EC. (2003). Relationships among supervisors' and subordinates' procedural justice perceptions and organizational citizenship behaviors. Academy of Management Journal, 46, 97-105. 
Tracey JB, Tews M. (2005). Construct validity of a general training climate scale. Organizational Research Methods, 8, 353-374.

Treviño LK, Brown BE. (2004). Managing to be ethical: Debunking five business ethics myths. Academy of Management Executive, 18, 69-81.

Tse HHM, Dasborough MT, Ashkanasy NM. (2008). A multi-level analysis of team climate and interpersonal exchange relationships at work. The Leadership Quarterly, 19, 195-211.

Turillo CJ, Folger R, Lavelle J, Umphress E, Gee J. (2002). Is virtue its own reward? Selfsacrificial decisions for the sake of fairness. Organizational Behavior and Human Decision Processes, 89, 839-865.

Walumba FO, Peterson SJ, Avolio BJ, Hartnell CA. (2010). An investigation of the relationships among leader and follower psychological capital, service climate, and job performance. PERSONNEL PSYCHOLOGY, 63, 937-963.

Wheeler L, Koestner R, Driver RE. (1982). Related attributes in the choice of comparison others. Journal of Experimental Social Psychology, 18, 489-500.

Wimbush JC, Shepard JM. (1994). Toward an understanding of ethical climate: Its relationship to ethical behavior and supervisory influence. Journal of Business Ethics, 13, 637-648.

Yukl G. (1998). Leadership in organizations (4th ed.). Englewood Cliffs, NJ: Prentice Hall.

Yukl G. (2004). Use power effectively. In Locke EA (Ed.), Handbook of principles of organizational behavior (pp. 242-247). Malden, MA: Blackwell.

Yukl G, Falbe CM. (1990). Influence tactics and objectives in upward, downward, and lateral influence attempts. Journal of Applied Psychology, 75, 132-140.

Yukl G, Falbe CM. (1991). The importance of different power sources in downward and lateral relations. Journal of Applied Psychology, 76, 416-423.

Zalesny MD, Ford JK. (1990). Extending the social information processing perspective: New links to attitudes, behaviors, and perceptions. Organizational Behavior and Human Decision Processes, 47, 205-246.

Zanna MP, Goethals GR, Hill JF. (1975). Evaluating a sex-related ability: Social comparison with similar others and standard setters. Journal of Personality and Social Psychology, 11, 86-93. 